placebo. Unlike the PFR data the $\mathrm{FEV}_{1}$ results showed no significant differences (see table) after three hours and at no time was there a significant difference between the effects of the two drugs. These results suggest that $\mathrm{FEV}_{1}$ and PFR measurements may not reflect identical aspects of airway resistance though generally they correlate well (Pride, 1971). They also indicate that when investigating cardioselectivity airway resistance should be assessed both at rest and during exercise.

Unlike the sympathetic stimulation induced by isoprenaline that occurring during exercise is physiological. Thus using exercise to assess beta-blocking activity is more likely to be clinically relevant except in the rare instances when beta-blocking drugs are used to counteract the effects of administered beta-agonists. Beta-blocking activity, as represented by reduction in exencise heart rate, may not parallel other criteria of cardiac beta-blockade so that equivalent cardioeffective concentrations of propranolol and practolol as determined in this study may not always be appropriate. Nevertheless, the results suggest that when either drug could be used to treat a cardiac disorder practolol is likely to have a less adverse effect on airway resistance than propranolol. This advantage of practolol may also be relevant in impending heart failure since any extra burden on ventilation may exacerbate the symptoms.

We thank the board of governors of St. Bartholomew's Hospital, the postgraduate committee in medicine, the University of Sydney, and the British Heart Foundation for financial support and I.C.I.
Ltd. for supplying propranolol and practolol. We appreciate the help and advice of Professor Paul Turner and Dr. John Hamer.

Requests for reprints should be sent to Dr. Marlin.

\section{References}

Bodem, G., et al. (1973). Fournal of Clinical Investigation, 52, 747.

Carruthers, S. G., et al. (1973). British Medical fournal, 2, 177.

Carruthers, S. G., et al. (1974). Clinical Pharmacology and Therapeutics, 15, 497.

Cleaveland, C. R., and Shand, D. G. (1972). Clinical Pharmacology and Therapeutics, 13, 181

Coltart, D. J., and Shand, D. G. (1970). British Medical fournal, 3, 731.

Connolly, C. K., and Batten, J. C. (1970). British Medical fournal, 2, 515. Fitzgerald, J. D., and O'Donnell, S. R. (1971). British fournal of Pharmacology, 43, 222 .

Jones, R. S., Buston, M. H., and Wharton, M. J. (1962). British fournal of Diseases of the Chest, 56, 78.

Kempthorne, O. (1952). The Design and Analysis of Experiments, p. 163. New York, John Wiley and Sons Inc.

Kumana, C. R., and Kaye, C. M. (1974). European fournal of Clinical Pharmacology, 7, 243.

MacDonald, A. G., Ingram, C. G., and McNeill, R. S. (1967). British Fournal of Anaesthesia, 39, 919 .

Marcelle, R., et al. (1968). Acta Allergologica, 23, 11

McNeill, R.' S. (1971). Postgraduate Medical fournal, 47, January Supple-

ment, 14.
Nicolaescu, V., Racoveanu, C., and Manicatide, M. (1973). European fournal of Clinical Pharmacology, 6, 3.

Paterson, J. W., et al. (1970). Pharmacologia Clinica, 2, 127.

Pride, N. B. (1971). British fournal of Diseases of the Chest, 65, 135.

Richardson, P. S., and Sterling, G. M. (1969). British Medical fournal, 3, 143.

Robinson, B. F., et al. (1966). Circulation Research, 19, 400.

Shand, D. G., Nuckolls, E. M., and Oates, J. A. (1970). Clinical Pharmacology and Therapeutics, 11, 112.

Turner, P., et al. (1971). Archives Internationales de Pharmacodynamie et de Thérapie, 191, 104 .

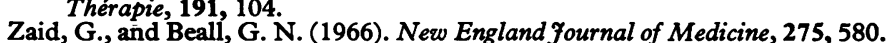

Ziskind, M., et al. (1973). Clinical Pharmacology and Therapeutics, 14, 137.

\title{
Carbohydrate Tolerence and Insulin Responses in Obstructive Jaundice
}

\author{
N. G. SOLER, P. D. EXON, A. PATON
}

British Medical fournal, 1974, 4, 447-449

\section{Summary}

Twenty-three patients with obstructive jaundice were given a 50-g oral glucose tolerance test (G.T.T.) and an insulin stimulation test with oral glucose and intravenous tolbutamide and glucagon. An abnormal glucose response was as common in patients with carcinoma of the pancreas (seven out of 12) as in patients with "other" causes of obstructive jaundice (six out of 11). Though both groups had a low and delayed insulin response the insulin levels were significantly lower in patients with carcinoma of the pancreas. After the insulin stimulation test patients with obstructive jaundice who did not have carcinoma of the pancreas had a greater and significantly different insulin response from patients with pancreatic cancer. There was, however, considerable overlapping between the results of individual patients in the two groups.

\section{Introduction}

Obstructive jaundice may present a difficult diagnostic problem. Clinical, biochemical, and radiological studies may not

Dudley Road Hospital, Birmingham B18 7 QH

N. G. SOLER, M.D., M.R.C.P., Senior Registrar

P. D. EXON, M.B., M.R.C.P., Sheldon Research Fellow

A. PATON, M.D., F.R.C.P., Consultant Physician identify the cause of the jaundice and a diagnosis is often reached only at laparotomy (Knill-Jones et al., 1973). Gall stones and carcinoma of the pancreas account for most cases but various other conditions such as drug-induced cholestasis or hepatitis may be responsible. Abnormal glucose tolerance has been reponted in $37 \%$ to $50 \%$ of patients with carcinoma of the pancreas (Murphy and Smith, 1963; Braganza and Howat, 1972) while ot her workers have shown a flat insulin response to glucose (McKiddie et al., 1969). According to Malins (1968) and Truelove and Reynell (1972) glycosuria and an abnormal glucose tolerance in a patient with obstructive jaundice favour a diagnosis of carcinoma of the pancreas.

Oral glucose tolerance and insulin responses have been studied in patients with obstructive jaundice due to various causes, before the diagnosis was established, to assess their predictive value. We have also used intensive pancreatic $\beta$ cell stimulation with glucose, tolbutamide, and glucagon to investigate whether insulin reserves in patients with carcinoma of the pancreas differ from those in other patients with obstructive jaundice.

\section{Patients and Methods}

Twenty-three patients with clinical and biochemical evidence of obstructive jaundice were studied (table I). A definite cause of the jaundice was later diagnosed at laparotomy in 20 patients. Of these, 12 had a carcinoma of the pancreas (half involving the head and half both the head 
TARLE I-Details of Patients Studied

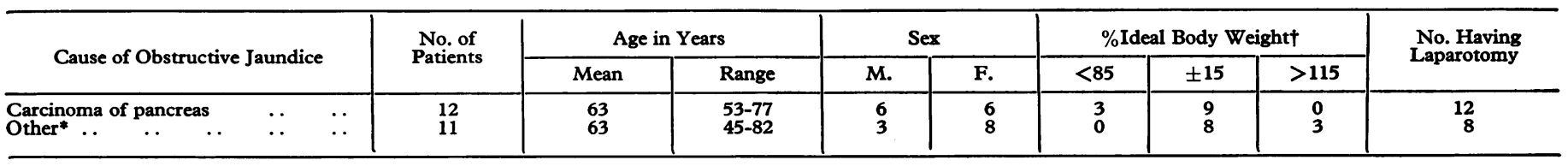

*This group comprised six patients with gall stones, four with drug-induced cholestasis, and one with hepatitis. tSociety of Actuaries (1962)

and body of the pancreas), six gall stones, one hepatitis, and one drug-induced cholestasis. In the three remaining patients there was strong presumptive evidence, supported by the liver biopsy findings, that the jaundice was related to drugs and surgery was not necessary.

All the patients were given a $50-\mathrm{g}$ oral glucose tolerance test (G.T.T.). Many were anorexic but for three days before the test they received a high-carbohydrate diet while remaining ambulant. After a 10-hour overnight fast the tests were performed at 9 a.m., the patients remaining seated throughout. An initial fasting venous blood specimen was withdrawn for blood sugar and serum insulin determinations and the patients then drank $50 \mathrm{~g}$ of glucose dissolved in $200 \mathrm{ml}$ of water. Further venous blood specimens were withdrawn at 30,60, 90, and 120 minutes for blood sugar and serum insulin determinations.

The day after the G.T.T. an insulin stimulation test was carried out using the intensive method of Ryan et al. (1967). Patients again fasted for 10 hours before the test. A fasting venous blood specimen was withdrawn and the patients then drank $75 \mathrm{~g}$ of glucose dissolved in $200 \mathrm{ml}$ of water. A second specimen was withdrawn at 30 minutes and this was followed by the rapid intravenous injection of $0.5 \mathrm{~g}$ of tolbutamide and $1 \mathrm{mg}$ of glucagon through an indwelling cannula in the opposite arm. Blood was again sampled for blood sugar and serum insulin determination $1,5,10$, and 30 minutes after the completion of this injection.

The Hoffman (1937) method on an AutoAnalyzer was used for blood sugar determinations, and serum insulin levels were measured using the double-antibody radioimmunoassay technique (Hales and Randle, 1963).

\section{Results}

The individual results of oral glucose loading in the 12 patients subsequently shown to have carcinoma of the pancreas and the 11 with obstructive jaundice due to other causes are shown in fig. 1. With the use of British Diabetic Association criteria (FitzGerald and Keen, 1964) seven patients with carcinoma of the pancreas and six "other" patients were shown to have a diabetic response. Patients with carcinoma of the pancreas gave generally low insulin responses (fig. 2) but only one had a completely flat response, and in this case the glucose tolerance curve was also flat. Most had a delayed insulin peak or a delayed fall or both. Patients with "other" causes of obstructive jaundice also often showed a delayed peak or fall in insulin.
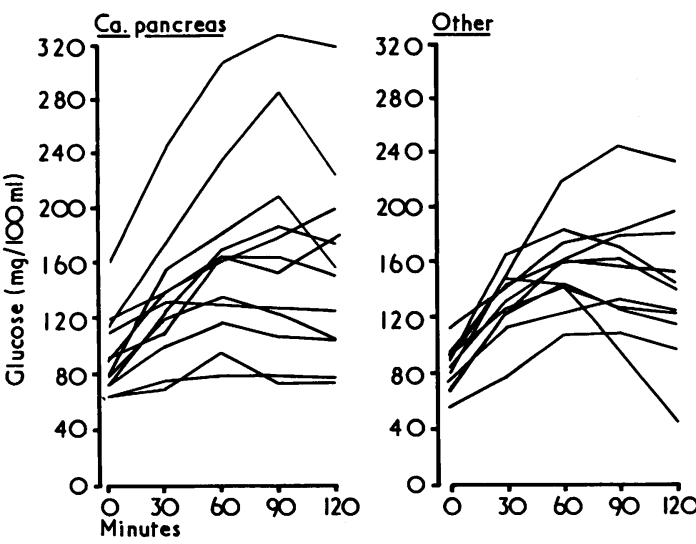

FIG. 1-Individual results of oral glucose loading $(50 \mathrm{~g})$ in patients with obstructive jaundice.
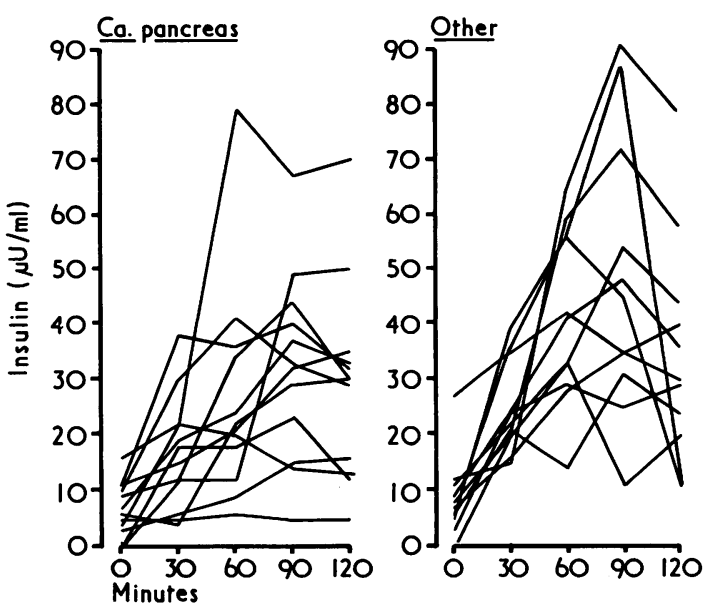

FIG. 2-Individual serum insulin levels during oral glucose loading in patients with obstructive jaundice.

The mean blood sugar and serum insulin levels during the G.T.T. in patients with carcinoma of the pancreas and those with "other" causes of the obstructive jaundice are shown in table II. Though the blood sugar curve was only marginally higher for the patients with pancreatic cancer the serum insulin levels were significantly lower at 30,60 and 90 minutes. The insulin response to intense pancreatic $\beta$-cell

TABLE II-Mean Blood Sugar and Serum Insulin Levels ( \pm S.D.) during 50-g Oral Glucose Loading

\begin{tabular}{|c|c|c|c|c|c|c|c|c|c|c|}
\hline & \multicolumn{5}{|c|}{ Blood Sugar (mg/100 $\mathrm{ml})$} & \multicolumn{5}{|c|}{ Serum Insulin $(\mu \mathrm{U} / \mathrm{ml})$} \\
\hline Time (min): & $\mathbf{0}$ & 30 & 60 & 90 & 120 & 0 & 30 & 60 & 90 & 120 \\
\hline $\begin{array}{lccc}\text { Carcinoma of pancreas } & . . \\
\text { Other } & . . & . & \ldots\end{array}$ & $\begin{array}{l}93 \pm 28 \\
84 \pm 16\end{array}$ & $\begin{array}{l}132 \pm 46 \\
132 \pm 23\end{array}$ & $\begin{array}{l}162 \pm 61 \\
157 \pm 30\end{array}$ & $\begin{array}{l}168 \pm 77 \\
154 \pm 42\end{array}$ & $\begin{array}{l}158 \pm 69 \\
141 \pm 51\end{array}$ & $\begin{array}{l}7 \pm 5 \\
9 \pm 7\end{array}$ & $\begin{array}{l}17 \pm 10 \\
25 \pm 8\end{array}$ & $\begin{array}{l}26 \pm 20 \\
41 \pm 16 \\
\end{array}$ & $\begin{array}{l}32 \pm 17 \\
48 \pm 26 \\
\end{array}$ & $\begin{array}{l}30 \pm 18 \\
35 \pm 21 \\
\end{array}$ \\
\hline Significance* & N.S. & N.S. & N.S. & N.S. & N.S. & N.S. & $P<0.025$ & $P<0.05$ & $\mathbf{P}<0.05$ & N.S. \\
\hline
\end{tabular}


TABLE III-Mean Blood Sugar and Serum Insulin Levels $( \pm$ S.D.) during Insulin Stimulation Tests

\begin{tabular}{|c|c|c|c|c|c|c|c|c|c|c|c|c|}
\hline \multirow[b]{2}{*}{ Time (min): } & \multicolumn{6}{|c|}{ Blood Sugar $(\mathrm{mg} / 100 \mathrm{ml})$} & \multicolumn{6}{|c|}{ Serum Insulin $(\mu \mathrm{U} / \mathrm{ml})$} \\
\hline & 0 & 30 & 31 & 35 & 40 & 60 & 0 & 30 & 31 & 35 & 40 & 60 \\
\hline $\begin{array}{l}\text { Carcinoma of pancreas } . . \\
\text { Other } \quad . . \quad \ldots \quad \quad \ldots\end{array}$ & $\begin{array}{l}98 \pm 36 \\
89 \pm 23\end{array}$ & $\begin{array}{l}161 \pm 59 \\
134 \pm 29\end{array}$ & $\begin{array}{l}175 \pm 69 \\
147 \pm 29\end{array}$ & $\begin{array}{l}188 \pm 52 \\
165 \pm 23\end{array}$ & $\begin{array}{l}199 \pm 58 \\
163 \pm 32\end{array}$ & $\begin{array}{l}211 \pm 56 \\
183 \pm 49\end{array}$ & $\begin{array}{l}9 \pm 6 \\
8 \pm 5\end{array}$ & $\begin{array}{l}19 \pm 12 \\
25 \pm 14\end{array}$ & $\begin{array}{r}84 \pm 64 \\
138 \pm 73\end{array}$ & $\begin{array}{r}89 \pm 62 \\
143 \pm 83\end{array}$ & $\begin{array}{r}89 \pm 50 \\
119 \pm 79\end{array}$ & $\begin{array}{r}79 \pm 32 \\
109 \pm 76\end{array}$ \\
\hline $\begin{array}{ll}\text { Significance* } & \ldots\end{array}$ & N.S. & N.S. & N.S. & N.S. & $P<0.05$ & N.S. & N.S. & N.S. & $P<0.05$ & $P<0.05$ & N.S. & N.S. \\
\hline
\end{tabular}

*Student's $t$ test.

*Student's $t$ test.
N.S. = Not significant.

stimulation was greater in patients with "other" causes of obstructive jaundice than in those with carcinoma of the pancreas and the maximum insulin response was significantly different at 31 and 35 minutes (table III). As indicated by the large standard deviations, however, considerable overlapping between the two groups occurred at all times during the test.

\section{Discussion}

The oral G.T.T. has remained in favour because of its simplicity and because it provides a physiological stimulus to gastrointestinal hormones that augment insulin secretion (Perley and Kipnis, 1967). Limitations in its interpretation, however, are important in this study. The prevalence of $a b-$ normal G.T.T. results in the general population increases with age, and by 50 years fewer than half of the tests give perfectly normal results (College of General Practitioners, 1963). Though our patients had a high-carbohydrate diet for a few days before the test they were often already malnourished. Delayed absorption of glucose as well as a nonspecific effect of jaundice on carbohydrate tolerance (Berkowitz et al., 1966) must also be considered in explaining the high proportion of abnormal results. In previous work (Murphy and Smith, 1963; Braganza and Howat, 1972) a high prevalence of diabetic responses to G.T.T.s was reported in patients with carcinoma of the pancreas but it was not made clear whether patients were already jaundiced when investigated. Our study suggests that patients with obstructive jaundice from causes other than carcinoma of the pancreas are just as likely to have a diabetic response to the G.T.T. On the other hand, Anderson et al. (1970) reported normal glucose tolerance when they studied five patients with carcinoma of the pancreas, four of whom were not jaundiced.

The low mean insulin response in patients with carcinoma of the pancreas was similar to that recorded by McKiddie et al. (1969). The higher insulin levels recorded in patients without carcinoma of the pancreas could be accounted for by the different weight distribution of the patients in the two groups under study. When the comparison of insulin levels was restricted to patients within $15 \%$ of their ideal body weight, however, the results remained significantly higher in patients who did not have carcinoma of the pancreas. Though the insulin responses were better in the latter group of patients they were still low and often showed a delayed peak. It is known that gall stones are often associated with pancreatitis, acute or chronic, which might alter insulin secretion, but a low insulin response occurred in patients with and without gall stones, suggesting that the pancreas may be affected in all cases of obstructive jaundice whatever the cause.

The insulin stimulation test used by other workers in investigating chronic pancreatitis (Joffe et al., 1968) showed similar responses to those in our patients with obstructive jaundice who did not have carcinoma of the pancreas. Patients with pancreatic cancer had significantly lower responses, suggesting destruction of the pancreatic islets. Post-mortem studies in patients who developed diabetes secondary to carcinoma of the pancreas, however, have shown that involvement by growth or associated pancreatitis may not be extensive and much of the gland may appear normal (Green et al., 1958; Schlesinger et al., 1960). Though the maximum insulin stimulation test separates the two groups of jaundiced patients with and without carcinoma of the pancreas, when individual results are analysed the degree of overlap is such that the test loses its value for diagnosis.

The distinction between medical and surgical causes of obstructive jaundice is important, and even in this small series two patients (one with hepatitis and one with drug jaundice) had unnecessary operations despite extensive investigation. Whether gall ston's or malignancy is responsible for surgical jaundice is of only secondary importance as exploratory laparotomy is indicated in either case. By the time carcinoma of the pancreas leads to obstructive jaundice, however, the growth is far advanced, and diagnosis at a much earlier stage is needed to achieve better results. Though diabetics more often develop carcinoma of the pancreas than do non-diabetics (Kessler, 1970) most cases of pancreatic cancer are not complicated by clinical diabetes (Bell, 1957; Green et al., 1958). Moreover, abnormal carbohydrate tolerance in obstructive jaundice is not necessarily related to an underlying carcinoma of the pancreas. A more important pointer to diagnosis is the onset of diabetes in middle age with weight loss out of proportion to the diabetic abnormality, which should always arouse suspicion of pancreatic disease.

\section{References}

Anderson, M. F., et al. (1970). Gut, 11, 524.

Bell, E. T. (1957). American Fournal of Pathology, 33, 499.

Berkowitz, D., Blinkoff, B., and Glassman, S. (1966). Gastroenterology, 50, 830. Braganza, J. M., and Howat, H. T. (1972). Clinics in Gastroenterology, 1, 219
College of General Practitioners (1963). British Medical fournal, 2, 655.

Fitzgerald, M. G., and Keen, H. (1964). British Medical fournal, 1, 1568. Green, R. C., Baggenstoss, A. H., and Sprague, R. G. (1958). Diabetes, 7, 308.

Hales, C. N., and Randle, P. J. (1963). Biochemical fournal, 88, 137.

Hoffman, W. S. (1937). Fournal of Biological Chemistry, 120, 51.

Joffe, B. I., et al. (1968). Lancet, 2, 890.

Kessler, I. I. (1970). Fournal of the National Cancer Institute, 44, 673.

Knill-Jones, R. P., et al. (1973). British Medical fournal, 1, 530 .

Knill-Jones, R. P., et al. (1973). British Medical fournal, 1, 530. $45,726$.

Malins, J. M. (1968). In Clinical Diabetes Melitus, p. 18. London, Eyre and Spottiswoode.

Murphy, R., and Smith, F. H. (1963). Medical Clinics of North America, 47,

397.
Perley, M. J., and Kipnis, D. M. (1967). Fournal of Clinical Investigation, 46, 1954.

Ryan, W. G., Nibbe, A. B., and Schwartz, T. B. (1967). Lancet, 1, 1255.

Schlesinger, F. G., Schwartz, F., and Wagenwoort, C. A. (1960). Acta Medica Scandinavica, 166, 337.

Society of Actuaries (1962). In Documenta Geigy, Scientific Tables, ed.

K. Diem, 6th edn., p. 623. Macclesfield, Geigy. 2nd edn., p. 684. Oxford, Blackwell Scientific. 